Przemysław Spryszak

Jagiellonian University, Cracow, Poland

e-mail: p.spryszak@iphils.uj.edu.pl

\title{
Berkeley on Certainty: A Dilemma
}

DOI: http://dx.doi.org/10.12775/RF.2015.010

It seems that Berkeley was deeply convinced that:

a) Immediate perception is certain (i.e. infallible, thus immune to sceptical doubts), whereas

b) Inference from what is immediately perceived to unperceived material things is not certain (in the aforesaid sense).

Compare the two propositions e.g. with par. 40 of Treatise:

"But say what we can, someone perhaps may be apt to reply, he will still believe his senses, and never suffer any arguments, how plausible soever, to prevail over the certainty of them. Be it so, assert the evidence of sense as high as you please, we are willing to do the same. That what I see, hear and feel doth exist, that is to say, is perceived by me, I no more doubt than I do of my own being. But I do not see how the testimony of sense can be alleged, as a proof for the existence of anything, which is not perceived by sense. We are not for having any man turn sceptic, and disbelieve his senses; on the contrary we give them all the stress and assurance imaginable; nor are there any principles more opposite to scepticism, than those we have laid down, as shall be hereafter clearly shewn." ${ }^{11}$

I think it can be justifiably held that these two propositions serve moreover as the pillars of Berkeley's system as a whole. At least, it is rather difficult to conceive how his idealistic and phenomenalistic phi-

1 G. Berkeley, Principles of Human Knowledge and Three Dialogues, ed. by H. Robinson, Oxford University Press, 1995, p. 40. For more evidence see especially par. 86 (p. 62). 
losophy could serve as a genuine answer to scepticism unless they are necessarily true. It is not my aim, however, to argue for or against them. ${ }^{2}$

Rather, what seems worth considering is the meaning as well as the reference of the term "certain" as applied above. My initial and, I suppose, quite evident point is that if Berkeley's system is to be recognized as plausible and cogent, this meaning and reference should not be only vaguely understandable, but they must in addition be explicable or analysable in perfect accordance with his philosophical position as well as within it.

I argue that though Berkeley's philosophy allows two (main, as we shall see) ways of required analysis, both of them, unfortunately, appear to have unexpected consequences. I shall accordingly outline these two ways in the following manner:

1) The term "certain" applied in the sentences above is analysable into abstract terms, referring to abstract objects, esp. insensible qualities of beliefs or insensible relations between such beliefs and evidence, or

2) The term "certain" (as applied above) is analysable into empirical terms (referring to ideas) or subjective terms (denoting minds or their operations).

2 I generally agree with Professor Pappas' detailed analysis of Berkeley's own notion of skepticism, hence I shall not concentrate on that issue here. See G. Pappas, Berkeley and Scepticism, "Philosophy and Phenomenological Research", Vol. 59, No. 1, 1999, pp. 133-149. What is more connected with my aim, however, is that Pappas is very well aware of the pivotal role which the propositions a) and b) seem to play in Berkeley's attempted refutation of skepticism. In the closing paragraphs of his paper Pappas remarks: "If 'immediately perceives' is non-epistemic in the sense just indicated, and describes a purely factual relationship between a person and a perceived entity, why think that immediately perceiving something yields knowledge, indeed as Berkeley says, certain knowledge? And in case of an individual idea $i$, why think that immediate perception of $i$ rules out even the logical possibility of mistaken belief, something Berkeley claims when he says "The objects I consider, I clearly and adequately know. I cannot be deceived in thinking I have an idea which I have not. (Introduction to Principles. In Works, Vol. 2, 39)". Pappas continues: “We can only give a partial answer to these questions, especially given the very little Berkeley says pertaining to them. The case for individual ideas that are immediately perceived is helped by noting that each such idea has all and only those non-relational properties it is perceived to have, a point we noted above. It is this claim which underwrites the view that individually perceived sensible ideas are perfectly known and objects of incorrigible belief. Matters are different with physical objects, as we have noted, because even when they are immediately perceived, not all of their non-relational properties are also immediately perceived. I think the most we can say is this: By the standards any of Berkeley's contemporaries would have found acceptable, if one's theory allows for immediate perception of physical objects, then that theory also provides for knowledge of such objects being gained by means of perception. Measured by these criteria then, Berkeley's refutation of skepticism would count as a success, whatever we might say of it when judging it by our lights." (pp. 148-149). 
It is not difficult to remark that acceptance of the first strategy would be disadvantageous for Berkeley's philosophical task. If the word "certain" refers to abstract objects, it obviously and necessarily belongs to the group of erroneous and superfluous terms refuted by Berkeley himself; it is unintelligible and has no definite nor consistent meaning at all. If it does have a meaning notwithstanding, then abstraction is possible after all, but then an opponent is given a right to maintain that it is equally possible to conceive material (unperceiving and unperceived) substances. The "abstractionalist" understanding of the notion of certainty forced by the first strategy is scarcely sustained by Berkeley's own positive theory of limited abstraction, outlined in the published Introduction to his Treatise, since that theory itself requires both elaboration and justification. The same can be said about the dubious idea that one can nevertheless form a sufficiently clear notion of certainty in the somewhat peculiar and rough sense of this term, so carefully adopted by Berkeley in the second edition of his major work.

It is necessary, however, to note that it would also barely be possible to understand certainty in the terms Berkeley employs particularly in De Motu in order to describe the nature of scientific explanation, which, perhaps, could at first glance suggest an alternative to the two ways discussed above (and below). First of all, "certainty" is not probably a scientific term at all: sciences like mathematics or physics do not take advantage of that expression, yet Berkeley (as a philosopher) does. Moreover, such treatment would make certainty another fiction (even if a convenient one), or at least would not support the claim that certainty is a genuine quality, in particular a quality of immediate perception. ${ }^{3}$ Last but not least, even if one would accept the understanding in question, the meaning of the term "certainty" (together with our ability to

3 The nature and extent of Berkeley's instrumentalism is discussed at a length in M. A. Hight, Berkeley Metaphysical Instrumentalism in S. Parigi (ed.), George Berkeley: Religion and Science in the Age of Enlightenment, Dordrecht: Springer, 2010, pp. 15-29. "We are now prepared to examine the details of my suggested interpretation of his instrumentalism. For Berkeley, both math and science depend on the manipulation of signs that stand for sensory content. And it is a gross error to confuse the usefulness of a theory for its truth, even if they often coincide. Science is one method for arriving at the truth, but should not be confused with the truth. For example, the concept of force is permissible in science, provided one understands force as a sign for certain kinds of empirical regularities - but there are no metaphysical things 'forces.' We can form no idea of force, but the word can serve the useful purpose of organizing the experiences we do have. Note that there is nothing about instrumentalism that precludes a theory from being true in its descriptions of the world; it must only be the case that even if its descriptions are true, only the utility of the theory matters. In our vulgar utterances we seem to refer to a material world. Yet all that we actually require to explain and function in the world are appeals to the regular ordering of our sensory ideas. As a result, Berkeley's instrumentalism is one about signs." (p. 19). 
grasp it) still would remain unexplained. Likewise, the thought that we are equipped with a limited faculty of comprehension called by that philosopher "reason" seems equally unconvincing. After all, granting his ontology, the nature and status of objects of the "faculty of reason" remains disputable anyway (to say the least), even supposing that one agrees to take that "rationalistic" concession honestly.

Surprisingly, the alternative does not turn out to be a more promising explanation. Two important points should be made. First, it is difficult to see how the term "certain" could signify spirits or their acts of will. Admitting this would be tantamount to an arbitrary linguistic decision, unwarranted by any plausible analysis of the concept of certainty, and for that very reason akin to the rejected assumption that material things do exist, unsupported, according to that philosopher, by any convincing analysis of sense perception. Secondly, the more promising and much more natural solution, that is, an analysis of certainty in terms referring only to ideas, fails as well, albeit for reasons which deserve more careful consideration.

Now, it appears that assuming Berkeley's modern "associationist" approach elaborated in his New Theory of Vision, the phenomenon of certainty of immediate perception ought to be reduced to the raw feeling (or sensation) of certainty, as directly presented to the mind as any other sensation or feeling. It is not a philosophical fiction at all, indeed, everyone frequently has that peculiar feeling of certainty, or that peculiar impression that something is (or is not) a case. Taking Berkeley's position for granted as such, would be, by all means, extremely dangerous to say that these subjective, raw feelings of certainty are marks or representations of objective certainty, or a criterion thereof, let alone an infallible one. When one accordingly says that immediate perception is certain, he can mean at best that the feeling or sensation of certainty has so often followed immediate perception that he is very inclined to treat the former as an intrinsic quality of the latter. Yet, notwithstanding how closely immediate perception and certainty appear to be linked, there is, according to Berkeley's theory in question, only an arbitrary, unnecessary and learned connection between them. ${ }^{4}$

Accordingly, the dilemma I am suggesting can be expressed in the following manner: granting Berkeley's philosophy, either the two aforesaid principles have de facto no meaning at all, due to the fact that the term "certain" must be disregarded as meaningless, or they are only contingently true and for that reason give no hope for absolutely certain empirical knowledge regarding what is immediately present to the mind.

4 I shall leave open the question of whether this way of understanding certainty is entirely devoid of logical perplexities. For instance, if immediate perception of that feeling is itself certain, it must be followed by another feeling of certainty, and so on. 
It goes without saying that to make this point it is necessary to not consider the two methods exclusively (regardless how extensive such consideration would be), but also to demonstrate that there are (beside the abovementioned quasi-scientific approach) no other solutions available, of which a supporter of Berkeley could take advantage in order to avoid or dissolve the dilemma. Naturally, at first sight this fact makes this point significantly harder to prove, because it would seem rather unconvincing if argued by someone who has actually considered all possible alternatives logically, philosophically and linguistically compatible with Berkeley's philosophy. The only thing one is able to do, then, is to discuss very briefly only those options which have some appearance of greater plausibility, and to reject them subsequently as implausible. I think there are thankfully only three reservations bearing the more visible mark of apparent cogency.

First and foremost, one can point out that the problem of defining certainty is obviously all too general and widespread in philosophy to give any legitimate cause for dismissing precisely Berkeley's construction. As a matter of fact, there is virtually no philosopher who can be said to have solved the problem of certainty. As a result, one cannot accuse Berkeley of failing where no other had succeeded, otherwise one would have to disqualify e.g. Plato's theory of ideas exactly for that reason that Plato, while seeking to secure knowledge of the world by making ideas objects of genuine knowledge, failed to define knowledge itself. ${ }^{5}$

However, one may find this answer to be insufficent. In fact, it is to be a tu quoque response (it is worth mentioning incidentally that Berkeley himself was perfectly aware of the soundness of this kind of answer), but it turns out to be rather an argument from authority, which he would certainly be eager to refuse. More importantly, it seems to rest on a serious logical mistake. The problem is not the fact that no one (Berkeley among others) has succeeded in defining certainty so far (let us grant this for argument's sake); the problem is that the definition seems to be impossible as long as one approves no philosophy other than Berkeley's. Indeed, if one is prone to allow "the space of reasons" as much as one allows sensation, one can at least entertain a hope of finding a proper formula (which is sometimes a reason why abstract objects are postulated). But if one happens to be a radical opponent of abstraction, then the chances become slim. It is worth mentioning that the argument does work if one assumes that the definition is impossible given any language and any philosophy, which is, alas, tantamount to scepticism, at least scepticism concerning the nature of certainty. Since I do not believe it is

5 As Gettier's counterexamples show in a quite straightforward manner. See of course E. L. Gettier, Is Justified True Belief Knowledge?, "Analysis", Vol. 23, No. 6, 1963, pp. 121-123. 
a line of argument this anti-sceptically oriented philosopher would ever approve, I shall turn to the second line.

Secondly, then, one can argue that there is a conceptual confusion lying behind the charge prematurely called "a dilemma" above. Now, one thing is to make knowledge of the external world possible and certain, the other is to be in a position to express the thought that knowledge of the external world is so. The charge assumes that the former implies the latter, hence that strong demand for conceptual resources which are arguably necessary for evoking that thought. But the difference is quite evident and not difficult to illustrate. One can, for instance, build a house that is big and white even if he is unable to grasp the respective proposition describing his work, much less to define houseness, bigness, or whiteness. Accordingly, it seems preposterous to demand that everyone who, colloquially speaking, rebuilds our knowledge should simultaneously be in a position to make and understand respective claims. In general, this is how scepticism as such can be overthrown, not solely that very narrow scepticism concerning Berkeley's philosophy: one thing is to have proved something, the other is to know (or to be aware) that something has been proved. For any anti-sceptical reaction, the former is at issue, while the latter is not necessarily required. ${ }^{6}$

Since I find such a response quite persuasive, I shall approach it in a more detailed manner. First of all, I think it is equally worth asking what lies behind that response itself. I suspect that it is the idea that there is no necessary connexion between doing something and knowing about that doing (both generally and colloquially speaking), in other words, it is assumed that the former does not have to be accompanied by the latter. Nevertheless, one can perfectly well argue that it still depends on a kind of "doing", whether it has to be so accompanied, or not. It is quite obvious that most of our physical activities, like the one mentioned in the example, need not to be followed by any form of awareness or any propositional attitudes. But if the activity in question is a mental activity, it can be quite the opposite. One should consider the example of being in pain: when someone is in pain, he or she knows that he or she is in pain and knows quite sufficiently what that very pain and that experience of being in pain is. Thus the question is: would someone's knowing of the world, for Berkeley, be more akin to a physical activity of building a house (con-

6 Incidentally, in his book Zagadnienia i kierunki filozofii, the Polish philosopher, Kazimierz Ajdukiewicz, (1890-1963) argued that the sceptic confuses the two by supposing a superfluous and perplexing linkage between them. The book was issued in 1949, thus several years before the discussion in English-language philosophy about so-called epistemic closure ever began. An English translation by $\mathrm{H}$. Skolimowski and A. Quinton was published by Cambridge University Press in 1973 as Problems and Theories of Philosophy. 
ceived realistically, i.e. as a non-mental activity, or a non-solely mental one), or rather to the mental activity of being in pain? It is hardly difficult to decide what the answer of the philosopher would be who denied the very existence of any non-mental activities. The outcome seems to be that one can indeed make a case against scepticism in the aforesaid way, provided they agree to naturalize our knowledge of the external world by equalling it to a physical (i. e. non-mental) activity, or to a bundle of such activities. If one however opposes, his role is to identify mental activities which have the very "non-sequitur" property presumably possessed by the building activity, that is, identify activities that are modes of awareness being at the same time not states of self-awareness. Alas, it can be said that this option is hardly accessible to Berkeley himself, owing to his debt to Cartesian theory of mind.

Thirdly, one can argue that quasi-problem unjustifiably labelled "a dilemma" here, has arisen exactly because the influence of the rationalistic Cartesian tradition on Berkeley's empiricist philosophy had been significantly overestimated. Indeed, what it was presumably demanded from Berkeley above amounts to showing a clear and distinct idea of certainty, as if the goal of his program was equally to provide with refined concepts adequately representing the reality. However, as soon as one draws their attention to the distinction between theory and practice approved by Descartes himself, as well as to Berkeley's own disapproval of representationalism, one will realize that it is practice which matters for the author of Three Dialogues. In other words, his own philosophy is for him only a convenient instrument whose function is to place us back in our initial position, where we can recognize as well as enjoy the beauty and reality of the sensual world, and where we would be able perform acts of will rightly supposing that God perceives them and will judge all of them accordingly. Therefore, there seems to be no point in pondering whether Berkeley managed to reconstruct our theoretical knowledge nor whether he was capable of grasping any clear and distinct idea of certainty. The issue is, at best, whether that precise tool had been properly designed.

It appears, however, that such an exceedingly pragmatic reading of Berkeley's philosophy, notwithstanding how tempting it may be, proves too much. After all, the reader is nevertheless inclined to assess his philosophy in terms of truth and falsity; if fact, Berkeley's readers together with critics always did so. Moreover, if the understanding of Berkeley's words were to be a mere vehicle to transport the reader into the place pointed out by Berkeley, then it seems that our old-new position is suitable actually not for an anima from Descartes' Meditations, but rather for an animalcule from Plato's Philebus. It is no wonder, therefore, that, to some extent, Berkeley altered his philosophical teaching in Siris, 
although it is plain that also this work can arguably be understood in accordance with the pragmatic interpretation mentioned above.

Perhaps one should conclude that an answer to scepticism can be given only by a philosophy that does not call into question or does not minimize abstract, formal or insensible conditions of our knowledge. From such a point of view, Berkeley's philosophy immediately dwindles down to a mere introduction, no matter how illuminating, to that type of philosophy - historically speaking, to Kantianism, and to Frege's or Husserl's antipsychologism.

Nonetheless, everything I am suggesting can be encapsulated in the question: "How to define (or word) certainty in purely Berkeleyan terms? How to identify its reference? If this apparently undemanding task cannot be accomplished altogether (as it seems), how anyone can reasonably maintain that taking Berkeley's viewpoint for granted is exactly what is sufficient to rescue our knowledge of the external world, that is, to make this knowledge certain?" One can be indeed quite at a loss here, and this is precisely what may bother the reader of any passage of his Treatise, Dialogues or of some of his other works.

\section{Bibliography}

K. Ajdukiewicz, Problems and Theories of Philosophy, transl. by H. Skolimowski and A. Quinton, Cambridge: Cambridge University Press, 1973.

G. Berkeley, Principles of Human Knowledge and Three Dialogues, ed. by H. Robinson, Oxford University Press, 1995.

G. Berkeley, The Works of George Berkeley, Bishop of Cloyne, ed. A. A. Luce and T. E. Jessop, vol. I-IX, London: Nelson, 1948-1957.

E. L. Gettier, Is Justified True Belief Knowledge?, „Analysis”, vol. 23, no. 6, 1963, pp. 121-123.

M. A. Hight, Berkeley Metaphysical Instrumentalism in S. Parigi (ed.), George Berkeley: Religion and Science in the Age of Enlightenment, Dordrecht: Springer, 2010, pp. 15-29.

G. Pappas, Berkeley and Scepticism, „Philosophy and Phenomenological Research", vol. 59, no. 1, 1999, pp. 133-149.

\section{Summary}

In this paper it is argued that it is a condition sine qua non of the success of Berkeley's anisceptic project that the concept of certainty (i.e. of infallibility, required in philosophy of his time and, according to Berkeley, plainly gained only by his immaterialist solution) have to be fully analysable in terms of his own philosophy, otherwise the very concept should be dismissed by him owing to 
its meaninglessness. I maintain that his philosophy makes two general ways of the analysis in question possible. I think, however, that both of them seem to have unexpected implications, especially in that it makes our empirical knowledge flowing from immediate perception become not absolutely certain. The alternative: meaninglessness of the term "certain" or uncertainty of that knowledge is what I call "a dilemma" here. Then I try to show that three additional ways of avoiding (or explaining) that dilemma, available assuming Berkeley's philosophy, i.e. the ways which probably remain in accordance with his position, unfortunately fail as well.

\section{Keywords}

George Berkeley, certainty, scepticism, perception, ideas, sensations, immaterialism. 